\title{
Post-secondary Student Perspectives on the Promising Practices for Teaching Online International Students
}

\author{
Clayton Smith, George Zhou, Michael Potter, Fatme Ammar \\ University of Windsor \\ Canada
}

\begin{abstract}
With the COVID-19 pandemic forcing postsecondary educational institutions to pivot to open and online learning, understanding the needs of international students is more important than ever before. This paper explores the connections between the promising practices for teaching online linguistically and culturally diverse international students and instructor characteristics with international student satisfaction. Using a qualitative research design, the study collected data through 15 individual interviews. Data analysis identified the teaching practices that resonate with international students. Recommendations for professional practice are discussed, along with potential areas for further research.
\end{abstract}

Keywords: Online, Open Learning, International Students, Student Satisfaction, Student Perceptions of Learning, COVID-19

\section{Introduction}

The current global pandemic, online learning has become the way most students across the world experience post-secondary education. Approximately $90 \%$ of all learning will be online during the time span of COVID-19 [1]. Although this shift to online learning was unplanned and involuntary, North American online education has seen a recent rise in popularity, even before the pandemic hit $[2,3,4]$.

Identifying strategies to teach culturally and linguistically diverse international students in online settings is essential to ensure the successful completion of courses by these students. Studies conducted by Grayson [5], He and Banham [6], and Kim et al. [7] discovered gaps in academic performance between international and native students. This is partially due to international students experiencing language difficulties, culturally-relatedlearning differences, academic support issues, and difficulties adjusting to a new educational system [8]. This contributes to international students being less satisfied with the student experience, and less engaged in the classroom than their native student peers [7].

The purpose of this study is to explore the connections between the promising practices for teaching online linguistically and culturally diverse international students and instructor characteristics, and international student satisfaction with these instructional practices. The following two research questions guided this study: (a) How satisfied are international online students with the online teaching strategies used by post-secondary instructors? (b) What post-secondary instructor characteristics do international students feel improve or hinder their online learning experiences?

\section{Literature Review}

The University of Windsor Teaching International Students Research Group conducted three studies that laid the groundwork for this study. Each of these studies examined student perspectives across an array of delivery approaches, including face-to-face, online, and distance learning. Their foundational study [9] found eight areas international students preferred, including academic integrity, assessment, assignments, clarifying expectations, communicating outside of the classroom, lecture design and delivery, verbal communications, and visual communications.

A follow-up study [10] investigated the relationship between individual student characteristics and students' satisfaction with promising international student teaching practices that revealed differences in several variables, including level of study, year of study, field of study, country of origin, length of time studying outside the country of origin and study location. Their third study [11] explored the differences between STEM (science, technology, engineering and mathematics) and nonSTEM international student perspectives that found differences between these two groups of students regarding student learning preferences and their perspectives on teaching approaches. With this foundation in place, a further examination of the literature revealed two main themes regarding student perspectives on the online teaching of diverse international student learners: (a) the importance of providing clear communication, and (b) ensuring instruction is student centered.

\subsection{Communication}

Clear communication is necessary for student success, including the academic success of international students. This includes building community and socialization. Encouraging student interaction in discussion boards and presence of the instructor are ways community and socialization can be accomplished [12]. Communication outside of the 
classroom is also important, as international students value instructor-student relationships [13]. When communicating with international students, it is also crucial to distinguish between basic proficiency and academic proficiency; these do not necessarily have to be related, as one does not precede the other [14]. Lastly, verbal and visual communication should be used to make lectures optimal for learning by paraphrasing, summarizing, and repeating difficult or key concepts, and by using diagrams, charts, and pictures $[14,15,16]$.

\subsection{Student-Centered Instruction}

For many international students, student-centered learning is a new experience as many of them come from a teacher-centered instructional culture. To enhance the online learning experience for international students, it is essential that a studentcentered learning orientation is provided, diverse student learning needs are understood, support class preparation is supported, and diversity and inclusion in the international student experience is appreciated.

Chen and Bennett [17] found that international students experience problems in acculturating to their online courses arose, at least in part, from a disconnect between their home and host educational cultures. Introducing students to western educational practices can greatly increase learning and student satisfaction [9]. Taking the time to understand the needs of each student in a classroom is essential for optimal learning and can be accomplished by acquiring knowledge of students' backgrounds and prior educational experiences [14], by assessing students' comfort with the use of educational technology [18], and by providing clear and constructive criticism on assignments [13].

Ensuring students come to class prepared is linked to higher learning outcomes and can be facilitated by encouraging students to complete readings before class, giving discussion assignments as homework, and giving tips on how to organize workload, online lectures, note-taking and studying [14,19,20,21]. Differentiated online instruction, such as the use of multi-modal instruction, can enhance support for students in isolated learning environments [22].

\section{Theory}

Our research study is guided by the work of four previous research studies. Tinto's student retention model [23], suggests that individual departure from post-secondary educational institutions results from a lengthy process of interactions between the individual and her/his connection with an institution's academic and social systems. Students who achieve academic and social integration, both formal and informal, increase their commitment to their careers and educational goals, and their post-secondary educational institutions. The study also relies on Darby and Lang's [12] research, which found that the personality of the professor can affect student learning. It is also influenced by the research conducted by Smith et al. $[9,10,11]$ on the relationships between student satisfaction and the promising practices for teaching culturally and linguistically diverse international students. Lastly, it is impacted by the Framework for Teaching and Learning for International Students, developed by Tran [24], which emphasized the importance of international student connections within their academic and social experiences. Figure 1 [11] shows how promising teaching practices, student satisfaction, and student perceptions of learning come together to create student persistence and educational success.

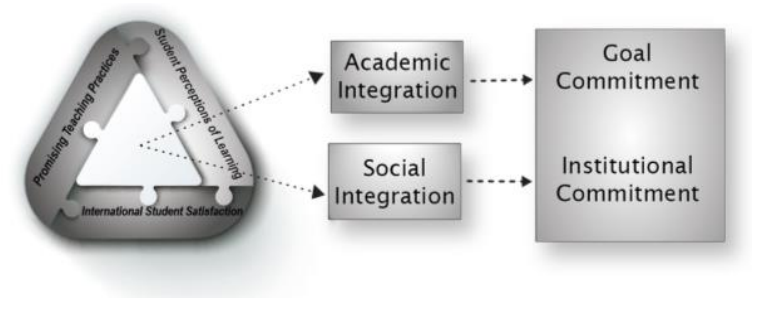

Figure 1. Identifying Effective Teaching Practices

\section{Method}

The research study used a qualitative research design, which included individual interviews. Interview participants were 15 international students from a wide variety of countries or origin, study levels, study stages, and ages located at a mid-sized, comprehensive university in Ontario, Canada. Graduate students made up 53\% of the total of participants. Seven students were in non-STEM academic programs (science, technology, engineering, and mathematics), while the remaining students were in STEM degree programs. Most interviewees were in Canada, with four residing in India, China, or the United States. Participants were recruited through individual emails, mass emails sent to the institution's international student list serve, class announcements, and verbal recommendations to fill out an online survey questionnaire to indicate their interest in the interviews. Interviews were conducted between November 2020 and February 2021. A prize draw ( $\$ 25$ prepaid credit card) was used to encourage participation.

\section{Results}

Generally, student-learning satisfaction was a mix of being satisfied and unsatisfied. Many students expressed appreciation for their instructor's hard work during these unprecedented times, but a greater 
number of students $(60 \%)$ indicated that online learning was not a comparable replacement. Although there were a variety of different perspectives on digital learning, the three primary factors that altered online learning for these students were communication, sense of belonging, and assessment practices. Table 1 presents a summary of the interviewees responses to the questions relating to these factors.

Table 1. Summary of Responses Regarding Primary Factors Associated with Open or Online Education

\begin{tabular}{|l|l|}
\hline Factor & Summary of Responses \\
\hline Assessment & $\begin{array}{l}\text { Students could not go back on a test once an answer was submitted. } \\
\text { Drastic differences in grades between group members of the same project were noticed. } \\
\text { Not enough variety: most courses just did multiple-choice tests. } \\
\text { Low grades for students who do not feel comfortable participating. } \\
\text { Marking done by graduate assistants was unfair and unorganized. } \\
\text { Some students believed the grading was fair. }\end{array}$ \\
\hline Communication & $\begin{array}{l}\text { Communication outside of the classroom shifted to digital conversations. } \\
\text { Concern with communication during lectures. } \\
\text { Concern with assignment feedback received. } \\
\text { Most students were satisfied with the communication received on classroom expectations. }\end{array}$ \\
\hline Belonging & $\begin{array}{l}\text { Lack of community in the online learning environment, although there were communication } \\
\text { tools used outside of the classroom. } \\
\text { Most student connections were through discussion boards, but not all instructors utilized this } \\
\text { feature. } \\
\text { Online learning was very isolated and stressful, and students felt they had to learn everything } \\
\text { on their own. } \\
\text { Questions and interactions were encouraged during class. } \\
\text { Students did not feel any discrimination and enjoyed it when they had group projects because } \\
\text { it allowed them to get to know their classmates. }\end{array}$ \\
\hline
\end{tabular}

Communication was the biggest change from face-to-face instruction noticed by international students receiving online or open education. Many emphasized the lack of communication in the digital world, whether it was experienced using asynchronous or synchronous approaches. One of the participants stated that "It's difficult to start discussion, or maybe I don't know this kind of communication," then continues to explain that her overall online learning experience was unsatisfactory for that reason. Poor communication during lectures (such as instructors speaking too quickly), unclear instructions on assignments, and lack of feedback all played to deceasing student satisfaction and student perceptions of learning. Most communication outside of the classroom shifted from in-person discussions to digital conversations through email or messaging applications.

The classroom climate was another element that changed when instruction pivoted to online, altering students' sense of belonging. Almost all participants agreed that there was a lack of community in the online-learning environment. One student explained, "I was actually lonely, and this is why I would never take asynchronous classes." Many students felt that they had to rely on themselves to learn the content, and did not know who to turn to for help. A few students also explained how the online classroom was stressful for them. Having to speak up during class made some students think twice before participating. Some instructors did their best to enhance belonging by calling out students by name; two students mentioned this during their interviews and said they appreciated the instructors' efforts.

Another way instructors enhanced students' sense of belonging and community was through group work. Many students enjoyed the group projects they had because it allowed them to get to know their classmates; however, two participants said there was no communication at all within their group, which rendered the group work less effective. This suggests that group work has great potential to build communities, but that instructors should encourage students to engage in active communication. When asked about the one thing students would change in the online classroom, almost all responded about how much they wanted to increase interaction with students and instructors. This could be done through discussion boards or group activities, but these formats have limitations that do not provide optimal opportunities for interaction. One student said that he really missed interacting with his colleagues in the classroom. Most students agreed there was student- 
centered learning and they appreciated efforts to engage then in this learning.

The change in assessment practices was the third primary factor that altered international student learning in online and open learning environments. The inability to go back on texts due to academic integrity concerns, lack of variety in assessment types, inconsistent grading done by graduate assistants, and lack of preparation for online learning were all ways the participants felt grading was impacted by the online pivot during the pandemic. Some students said that they think they are doing just as well as they would have if the courses were in person. To increase the chances of a positive experience, most students would benefit from two educational practices: (a) graduate assistants should be trained for online teaching and learning, and (b) instructors should use a variety of teaching and assessment approaches. There are some other notable differences that students voiced worth mentioning. Some instructors did not incorporate culturally-responsive teaching in their courses. Those who did see this in their classrooms said it was nice to experience different cultures in the course content, but a few said that it did not make much a difference for their learning. Some participants emphasized the fear of speaking due to their accents. Many students noted the lack of differentiated instruction. One student did see this teaching practice but said the failed attempt of using a translator online caused the student to drop the course.

One student said, that "The problem is when students go to the groups in online; they all talk and it's difficult." Although many students were aware that if there was an issue, they could contact the instructor through email or office hours. When it comes to group work, though, some students were unhappy with the effort put in by their teammates. Many preferred to pick their own groups so they can work with peers they trust. One student appreciated the peer evaluation forms they completed as a way to make the instructor aware of individual participation. Another student said that although these forms are helpful, he doubted anyone would say anything negative about group teammates. With respect to group assignments, instructors should consider how they expect students to engage with one another and provide guidelines and frequent spaces for student feedback. Most students preferred synchronous learning, although a few students noted that a positive aspect of asynchronous was the flexibility. They could watch the lecture on their own time and speed up, slow down, or pause the video as many times as needed.

Almost all participants agreed that the online platform was easy to use, with some students saying they received a short tutorial on how to use the site. One student said she was not taught how, and they expected this instruction beforehand. She had to explore and figure out how to use the platform on her own. Another student said some instructors need more training on the online platform to make the classes move along more smoothly. Some instructors used more than one platform, but one student noted that it would be easier if just one was used, so that everything was in one place. In addition, Internet connectivity was an issue at times.

Students also enjoyed it when professors made jokes and used humor, as it made the classroom environment more interactive.

\section{Discussion and Conclusion}

Our study also shows how the change to online learning has affected culturally and linguistically diverse international students. The literature stated the importance of clear communication [15], building community within the classroom [12], and fair assessment practices [25], and from our findings, we noticed that the negative perception of online learning was due to the lack of these practices. Students felt isolated and alone, and the change to online learning left them confused about how to be students. The literature states that this plays a big role in how students acculturate to online learning [17] and here we see the effects of the lack of community in the online setting. Silence during class, lack of interaction, and new ways of grading created a difficult adjustment for many students. Efforts made to build community were not always successful: group work was appreciated, but some students did not do their fair share of the work; discussion boards were not always used; and students did not participate because of their accents when speaking. The literature also emphasized the value of student-centered teaching [14], and our findings aligned with this statement, as this practice was one that almost all participants agreed was present and one that shed a positive light on the online-learning experience. We also found that there are individual instructor characteristics preferred by online international students, including calling on students by name, use of humor and jokes, and being understanding of the current global situation and how that is affecting students.

\section{Recommendations for Professional Practice}

Educators who have international students in their online classrooms should continue to use the promising teaching practices as they created increased satisfaction and increased perceptions of learning. Some of the most impactful teaching practices (e.g., clarifying classroom expectations, being aware of diversity and inclusion, fostering a positive online learning environment, and focusing on studentcentered teaching) should be incorporated into instruction. With the unanticipated changes that came 
with COVID-19, it is important that institutions work to continue to provide instructors with professional development by following, and building on, the promising teaching practices that relate to student satisfaction and student perceptions of learning.

\section{Study Limitations and Suggestions for Future Research}

As further research is contemplated, there is a need to learn more about the online and open experiences of post-secondary international students. Following the pandemic experience and the maturation of instructor use of the promising practices for teaching online international students, it will be helpful to study international student perspectives on open and online learning. We recommend that this be done at a variety of institution types in various cultural contexts. This study had limitations that need to be acknowledged, which may limit generalization of the results. It was conducted at one mid-sized Canadian university, and incorporated responses from only 15 research participants. The perceptions of student learning data is self-reported, which makes it hard to discern how much learning can be accurately associated with each teaching practice. The study was completed in one semester and is based on only one semester of data. Research conducted for the full academic year may have created more response diversity. While research findings help to understand student satisfaction with online teaching practices, care should be taken in generalizing results beyond the research site. Notwithstanding these limitations, this study demonstrates that international students are only slightly satisfied with the online and open teaching practices, and the individual characteristics of their instructors.

\section{References}

[1] J. Radcliff, D. Aaron, J. G. Sterle, M. von Keyserlingk, N. Irlbeck, M. Maquivar, M. Wulster-Radcliffe, and C. Jones, "Moving Online: Roadmap and Long-term Forecast", Animal Frontiers, Oxford, UK, 2020, pp. 3-45.

[2] T. Bates, T. Donovan, N. Johnson, and J. Seamen, Tracking Online Education in Canadian Universities: National Survey of Online Digital Learning, Canadian Digital Learning Association, 2019. http://www.cdlra-acr fl.ca/wp-content/uploads/2020/07/2019_national_en.pdf. (Access Date: 13 September 2021).

[3] A. S. Ginder, J. E. Kelly-Reid, and F. B. Mann, Enrollment and Employees in Postsecondary Institutions, Fall 2016; and Financial Statistics and Academic Libraries, Fiscal Year 2016, National Center for Education Statistics, Washington, DC, 2017. https://nces.ed.gov/pubs2018/2018 002.pdf. (Access Date: 18 September 2021).
[4] J. Cook, "Online Education and the Emotional Experience of the Teacher", New Directions for Teaching and Emotion, Hoboken, NJ, 2018, pp. 67-75.

[5] J. P. Grayson, "The Experiences and Outcomes of Domestic and International Students at Four Canadian Universities", Higher Education Research and Development, London, UK, 2008, pp. 215-230.

[6] Y. He, and H. C. Bahnam, "International Student Academic Performance: Some Statistical Evidence and its implications", American Journal of Business Education, Bingley, UK, 2011, pp. 89-100.

[7] Y. K. Kim, D. Edens, M. F. Iorio, C. J. Curtis, and E. Romero, "Cognitive Skills Development Among International Students at Research Universities in the United States", Journal of International Students, Baltimore, MD, 2015, pp. 526-540.

[8] C. Smith, "Promoting International Student Success", The AACRAO International Guide: A Resource for International Education Professionals, American Association of Collegiate Registrars and Admissions Officers, Washington, DC, 2016, pp. 105-115.

[9] C. Smith, G. Zhou, M. Potter, and D. Wang, "Connecting Best Practices for Teaching Linguistically and Culturally Diverse International Students with International Student Satisfaction and Student Perceptions of Student Learning", Advances in Global Education and Research, Tampa, FL, 2019, pp. 252-265.

[10] C. Smith, G. Zhou, M. Potter, D. Wang, M. Pecoraro, and R. Paulino, "Variability by Individual Student Characteristics of Student Satisfaction with Promising International Student Teaching Practices, Literacy Information and Computer Education Journal, Basel, Switzerland, 2019, pp. 3160-3169.

[11] C. Smith, G. Zhou, M. Potter, D. Wang, F. Menezes, G. Kaur, and G. Danko, "Connecting Best Practices for Teaching International Students with Student Satisfaction: A Review of STEM and Non-STEM Student Perspectives, Multidisciplinary Perspectives on International Student Experience in Canadian Higher Education, IGI Global, Hershey, PA, 2021, pp. 63-80.

[12] F. Darby, and J. Lang, Small Teaching Online, John Wiley and Sons, Hoboken, NJ, 2019.

[13] C. Paralejas, "A Case Study of Understanding the Influence of Cultural Patterns on International Students' Perception and Experience with Online Learning," ProQuest Dissertation and Theses Global, Ann Arbor, MI, 2013.

[14] K. Kinsella, "Creating an Enabling Learning Environment for Non-native Speakers of English," Multicultural Course Transformation in Higher Education: A Broader Truth, Allyn and Bacon, Boston, 1997, pp. 104125 .

[15] A. Haque, Teaching Inclusively: Helping Students Overcome Academic Culture Shock. Western University Teaching Support Centre, London, ON, 2004. 
[16] F. Jiminez, "Creating Linguistically Inclusive Classrooms", Inside Higher Ed. Retrieved from https://www.insidehighered.com/blogs/gradhacker/creating -linguistically-inclusive-classrooms. (Access Date: 13 October 2021).

[17] R. T.-H. Chen, and S. Bennett, "When Chinese Learners Meet Constructivist Pedagogy Online", Higher Education, New York, NY, 2012, pp. 677+.

[18] X. Woodley, C. Hernandez, J. Parra, and B. Negash, "Celebrating Difference: Best Practice in Culturally Responsive Teaching Online", TechTrends, New York, NY, 2017, pp. 470-478.

[19] W. Hwang, and G. Hsu, "The Effects of Pre-reading and Sharing Mechanisms on Learning with the Use of Annotations," Turkish Online Journal of Educational Technology, Sakarya, Turkey, 2011, pp. 234-249.

[20] T. Lineweaver, "Online Discussion Assignments Improve Students' Class Preparation, Teaching of Psychology, Thousand Oaks, CA, 2010, pp. 204-209.

[21] A. Macgregor. and G. Folinazzo, "Best Practices in Teaching International Students in Higher Education: Issues and Strategies, TESOL Journal, Hoboken, NJ, 2017.

[22] L. Mestre, and B. Woodard, "Accommodating Diverse Learning Styles in an Online Environment, American Library Association, 2006, pp. 27-32.

[23] V. Tinto, Leaving College: Rethinking the Causes and Cures of Student Attrition, University of Chicago Press, Chicago, IL, 1993.

[24] L. T. Tran, "Teaching and Engaging International Students: People-to-People Connections and People-toPeople Empathy", Journal of International Students, Baltimore, MD, 2020, pp. xii-xvii.

[25] K. Beck, Being International: Learning in a Canadian University, unpublished doctoral dissertation, Simon Fraser University, Vancouver, BC, 2008. 